\title{
Produksi selada (Lactuca sativa l.) dengan penyinaran lampu led merah dan biru di malam hari pada teknologi hidroponik sistem terapung termodifikasi
}

\author{
(Production of lettuce (Lactuca sativa L.) on hydroponic technology of floating system with \\ red and blue Light Emitting Diode at night)
}

\author{
A. A. Suhandoko, Sumarsono, dan E. D. Purbajanti \\ Agroecotechnology, Faculty of Animal and Agricultural Sciences, Diponegoro University \\ Tembalang Campus, Semarang 50275 - Indonesia \\ Corresponding E-mail: ardiansyahazhary@gmail.com
}

\begin{abstract}
This research has an aim to observe the production of lettuce (Lactuca sativa L.) on hydroponic technology of floating system with red and blue LED (Light Emitting Diode) at night. This research was conducted inside the Screenhouse in which located on the top of Griya Kads House building, Bulusan Village, Tembalang Sub-district from May to June 2017. The research was conducted by $3 \times 3$ factorial experiments in Nested Design with 3 replications. The first factor was $0,1.5$ and 3 hours irradiation of red and blue LED lights at night. The second factor was 3, 5 and $7 \mathrm{ml} /$ liter of AB mix nutrient concentration which was nested in the first factor. The data collected were fresh weight, dry weight and root canopy ratio. The results of the study showed that the treatment of AB mix nutrient concentration had no significant effect on all parameters. The production of lettuce with level of $5 \mathrm{ml}$ concentration of AB mix was quite good, yet $3 \mathrm{ml}$ and $7 \mathrm{ml}$ levels didn't improve lettuce production. The duration of red and blue LED irradiation only resulted in an increase in the production of canopy fresh weight. This research can be concluded that 3 hours was sufficient to give the good results to improve the results of lettuce plants production.
\end{abstract}

Keywords : Lettuce Production, AB Mix Nutrition, Red and Blue LED.

\begin{abstract}
ABSTRAK
Penelitian ini memiliki tujuan untuk mengetahui produksi selada (Lactuca sativa L.) pada teknologi hidroponik sistem terapung termodifikasi dengan penyinaran lampu LED (Light Emitting Diode) merah dan biru di malam hari. Penelitian ini dilaksanakan di dalam screenhouse yang ada di dak atas bangunan Rumah Griya Kads, Kelurahan Bulusan, Kecamatan Tembalang dari bulan Mei-Juni 2017. Penelitian dilaksanakan dengan percobaan faktorial 3x3 dalam rancangan tersarang (Nested Design) dengan 3 ulangan. Faktor pertama adalah $0,1,5$ dan 3 jam penyinaran cahaya lampu LED merah dan biru pada malam hari. Faktor kedua adalah 3, 5 dan $7 \mathrm{ml} /$ liter konsentrasi nutrisi $\mathrm{AB}$ mix yang tersarang pada faktor pertama. Data yang dikumpulkan adalah berat segar, berat kering dan rasio tajuk akar. Hasil dari penelitian memperlihatkan bahwa perlakuan konsentrasi nutrisi ab mix tidak berpengaruh nyata terhadap semua paramater. Produksi selada dengan taraf $5 \mathrm{ml}$ konsentrasi AB mix telah cukup memberikan hasil yang baik, namun taraf $3 \mathrm{ml}$ dan $7 \mathrm{ml}$ tidak menambahkan hasil produksi selada. Durasi penyinanaran lampu LED merah dan biru, hanya menghasilkan peningkatan produksi berat segar tajuk. Penelitian dapat diambil kesimpulan yaitu 3 jam sudah cukup memberikan hasil yang baik untuk meningkatkan hasil produksi tanaman selada.
\end{abstract}

Kata kunci: Produksi Selada, Nutrisi AB Mix, Lampu LED Merah dan Biru. 


\section{PENDAHULUAN}

Indonesia terus mengalami pertumbuhan penduduk. Berdasarkan hasil sensus BPS (2010), dari tahun 2000 hingga 2010 penduduk tahun 2000 berada pada 205 juta jiwa dan mencapai 237 juta jiwa hasil sensus penduduk tahun 2010. Pertumbuhan penduduk ini menjadikan kebutuhan sumber makanan sehat semakin bertambah seiring dengan semakin besarnya konversi lahan pertanian ke lahan non pertanian. Hal ini memberikan kendala bagi kegiatan budidaya pertanian terutama dalam penyediaan lahan. Sehingga dalam mengatasi hal ini adalah dengan menggunakan sistem pertanian laham sempit. Hidroponik menjadi salah satu sistem pertanian lahan sempit yang dapat menyiasati keterbatasan lahan di perkotaan secara efisien dan efektif.

Hidroponik adalah salah satu metode dalam pertanian yang mengusung budidaya tanaman tanpa menggunakan tanah sebagai media tanamnya, melainkan air yang dicampurkan nutrisi dan juga oksigen untuk pertumbuhan bagi tanaman (Samanhudi dan Harjoko, 2006). Penggunaan sistem hidroponik dapat menghasilkan tanaman budidaya dengan penggunaan air dan pupuk yang tepat. Selain itu, hidroponik tidak terkendala oleh musim sehingga hal ini memberikan keuntungan dalam menciptakan produksi berkelanjutan dan. Budidaya sayuran daun hidroponik umumnya menggunakan larutan hara berupa larutan hidroponik standar ( $\mathrm{AB}$ mix), yang terdiris dari larutan A (hara makro) dan larutan B (hara mikro).

Pada saat ini, komoditas hortikultura khususnya tanaman sayur menjadi pendukung pemenuhan kebutuhan pangan Indonesia. Peningkatan permintaan dari komoditas hortikultura terutama sayur yang berkualitas di Indonesia, menjadikan Hidroponik tepat digunakan dalam pembudidayaan tanaman hortikultura. Menurut hasil survei BPS (2010), konsumsi sayuran di Indonesia meningkat dari 31,790 kg pada tahun 1996 menjadi 44,408 kg per kapita per tahun pada tahun 1999, sehingga seiring waktu berjalan, menjadikan pengeluaran sayur semakin mahal untuk dibeli konsumen. Hal ini memberikan peluang bagi hidroponik.

Salah satu tanaman sayur yang pemasarannya meningkat seiring dengan pertumbuhan ekonomi, jumlah penduduk dan konsumsi per kapita adalah selada. Selada merupakan tanaman berhari panjang, dengan pertumbuhan dan perkembanganya melebihi dari 12 jam intensitas penyinaran cahaya. Peningkatan dari pertumbuhan dan perkembangan tanaman hari panjang, dapat dilakukan dengan pemberian perlakuan terhadap fotoperiodisme yang dapat mempengaruhi produksi tanaman. Pemberian perlakuan fotoperiodisme tanaman hari panjang, dapat dilakukan dengan memanipulasi panjang hari menggunakan lampu LED (light emitting diode). LED membutuhkan energi listrik yang rendah dan tidak mengeluarkan suhu tinggi. Hal ini dapat menjadikan LED merah dan biru sebagai alternatif manipulasi fotoperiodisme tanaman selada dengan sistem hidroponik.

Berdasarkan informasi yang dijelaskan diatas, penelitian ini memiliki tujuan untuk mengetahui produksi tanaman selada (Lactuca sativa L.) pada teknologi hidroponik sistem terapung (THST) termodifikasi dengan penyinaran lampu LED (Light Emitting Diode) merah dan biru di malam hari. Adapun manfaat dari penelitian ini adalah untuk memberikan informasi tentang peningkatan produksi tanaman selada pada teknologi hidroponik sistem terapung dengan penyinaran cahaya lampu LED dan kombinasi konsentrasi larutan nutrisi $\mathrm{AB}$ mix terhadap.

\section{MATERI DAN METODE}

\section{Materi}

Penelitian ini dilaksanakan di dalam screenhouse yang ada di dak atas bangunan Rumah Griya Kads, Kelurahan Bulusan, Kecamatan Tembalang dari bulan Mei-Juni 2017 dan di Fakultas Peternakan dan Pertanian, Universitas Diponegoro. Penelitian dilakukan dari bulan April-Juni 2017.

\section{Metode}

Penelitian dilaksanakan dengan percobaan faktorial 3x3 dalam rancangan tersarang (Nested Design) dengan 3 ulangan. Faktor pertama adalah 0 jam penyinaran (L0), 1,5 jam penyinaran dan 3 jam penyinaran cahaya lampu LED merah dan biru pada malam hari. Faktor kedua adalah 3 
$\mathrm{ml} /$ liter (N1), $5 \mathrm{ml} /$ liter $(\mathrm{N} 2)$ dan $7 \mathrm{ml} /$ liter $(\mathrm{N} 3)$ konsentrasi nutrisi $\mathrm{AB}$ mix yang tersarang pada faktor pertama.

Prosedur penelitian dimulai dengan mempersiapkan tempat penelitian, yaitu membangun screenhouse dan pemasangan lampu LED merah dan biru pada tempat penelitian. Sebelum penelitian disiapkan alat dan bahan penunjang penelitian, serta proses persemaian. Penelitian dimulai ketika kondisi sccreenhouse telah siap pakai dan tanaman semai telah siap tanam. Penelitian lalu dimulai dengan persiapan nutrisi $\mathrm{AB}$ mix dan penanaman tanaman semai. Pergantian air nutrisi dan pengecekan $\mathrm{pH}, \mathrm{EC}$ dan TDS, dilakukan setiap minggu hingga waktu panen tiba. Panen dilakukan ketika umur tanaman selada berada pada 30 HST. Analisis tanaman dilakukan setelah panen di Laboratorium Ekologi dan Produksi Tanaman, Fakultas Peternakan dan Pertanian, Universitas Diponegoro.

Data yang dikumpulkan adalah 1) berat segar tajuk, akar dan total (gram) dilakukan dengan menggunakan timbangan analitik, 2) berat kering tajuk, akar dan total (gram) dilakukan dengan pengeringan di oven pada $105^{\circ} \mathrm{C}$ selama $1 \times 24$ jam dan menggunakan timbangan analitik, 3) rasio tajuk akar menggunakan perbandingan berat kering tajuk dan akar.

Data yang telah diperoleh diperiksa koefisien keragamanya dan dianalisis menggunakan analisi ragam dan uji lanjut pembanding nilai tengah dengan Uji Beda Nyata Jujur (BNJ) atau Tukey Honestly Significance Difference (HSD) Test dengan taraf ketelitian 5\%.

\section{HASIL DAN PEMBAHASAN}

\section{Berat Segar}

Berdasarkan hasil analisis ragam berat segar, meskipun berat segar tajuk tidak nyata dipengaruhi konsentrasi $\mathrm{AB}$ mix, tetapi hanya berat segar tajuk yang berpengaruh nyata $(\mathrm{P}<0,05)$ dipengaruhi penyinaran lampu LED. Data hasil pengujian disajikan pada Tabel 1 .

Berdasarkan hasil dari uji lanjut BNJ berat tanaman yang tersaji pada Tabel 1, diperoleh hasil bahwa berat segar tajuk terbesar diperoleh pada perlakuan penyinaran lampu 3 jam yang nyata $(\mathrm{P}<0,05)$ lebih berat dibanding penyinaran lampu 1,5 jam, namun tidak nyata $(\mathrm{P}<0,05)$ lebih berat dibanding penyinaran lampu 0 jam (kontrol). Hal

Tabel 1. Produksi Berat Segar akibat Penyinaran Lampu LED

\begin{tabular}{|c|c|c|c|c|}
\hline \multirow{3}{*}{$\begin{array}{l}\text { Penyinaran } \\
\text { Lampu LED }\end{array}$} & \multirow{3}{*}{$\begin{array}{c}\text { Konsentrasi } \mathrm{AB} \\
\text { Mix }\end{array}$} & \multicolumn{3}{|c|}{ Rerata Berat Segar } \\
\hline & & \multicolumn{3}{|c|}{ Umur Tanaman } \\
\hline & & Tajuk & Akar & Total \\
\hline \multirow{2}{*}{$\ldots . . .($ jam $) .. . . .}$. & $\ldots . . .(\mathrm{ml} / \mathrm{l}) \ldots . .$. & & $\ldots$ (g)... & \\
\hline & 3 & 77,00 & 18,29 & 95,29 \\
\hline \multirow{4}{*}{0} & 5 & 52,50 & 14,12 & 66,62 \\
\hline & 7 & 65,50 & 11,12 & 76,62 \\
\hline & Rata-rata & $65^{\mathrm{ab}}$ & $14,51^{\mathrm{a}}$ & $79,51^{\mathrm{a}}$ \\
\hline & 3 & 58,83 & 22,29 & 81,12 \\
\hline \multirow{2}{*}{1,5} & 5 & 49,33 & 13,62 & 89,96 \\
\hline & 7 & 56,83 & 23,29 & 80,12 \\
\hline \multirow{5}{*}{3} & Rata-rata & $55^{\mathrm{b}}$ & $19,73^{\mathrm{a}}$ & $83,73^{\mathrm{a}}$ \\
\hline & 3 & 75,17 & 16,29 & 91,46 \\
\hline & 5 & 91,33 & 18,79 & 110,12 \\
\hline & 7 & 76,50 & 20,12 & 96,62 \\
\hline & Rata-rata & $81^{\mathrm{a}}$ & $18,40^{\mathrm{a}}$ & $99,40^{\mathrm{a}}$ \\
\hline \multicolumn{2}{|c|}{ Respon } & $*$ & tn & tn \\
\hline \multicolumn{2}{|c|}{ KK (\%) } & 29,63 & 30,74 & 22,65 \\
\hline
\end{tabular}

Keterangan : * : berbeda nyata; tn : tidak berbeda nyata; KK : koefisien keragaman; Angka yang diikuti oleh huruf yang sama pada kolom yang sama menunjukkan berbeda tidak nyata pada taraf $5 \%$ menurut Uji Beda Nyata Jujur (BNJ). 
ini menunjukkan bahwa perlakuan LED dengan penyinaran lebih lama (3 jam), mempunyai pengaruh yang sama dengan perlakuan tanpa penyinaran ( 0 jam/kontrol $)$ dalam membantu pertumbuhan berat segar tajuk. Perlakuan lampu LED yang lebih lama (3 jam) lebih baik pengaruhnya daripada tanpa penyinaran (0 jam). Hal ini menunjukkan pemberian cahaya LED dengan penyinaran paling lama (3 jam), dapat membantu tanaman selada berfotosintesis dengan baik. Hal ini didukung oleh pendapat Johkan et al. (2010) yang menyatakan bahwa cahaya biru LED sesuai dengan panjang gelombang yang dibutuhkan selada, sehingga dapat menstimulus biomassa. Luas daun yang berbeda nyata pada lama penyinaran 3 jam juga memiliki keterkaitan. Kondisi ini sesuai dengan pendapat Gardner et al. (2007) yang menyatakan bahwa tingkat perkembangan luas daun yang tinggi dapat memungkinkan penangkapan cahaya per satuan volume secara maksimal dan meminimalkan jarak yang harus digunakan $\mathrm{CO}_{2}$ dari permukaan kloroplas sehingga berpengaruh pada jumlah fotosintat yang dihasilkan.

Pada kondisi fotosintat yang banyak, tanaman dapat membentuk biomassa untuk pembentukan jaringan dan organ pada tubuhnya seiring dengan masa pertumbuhan. Hal ini sesuai dengan pendapat dari Guritno dan Sitompul (2006) yang menyatakan bahwa produksi biomassa pada tanaman dapat menambah berat dan menambah ukuran yang dapat diukur secara kuantitaif. Pemberian kondisi lingkungan yang sesuai dan cukup dapat membantu tanaman dalam menambah biomassa, yang akan berbanding lurus dengan berat segar tanaman. Alasan berat segar akar dan total tidak berbeda nyata pada penyinaran lampu, dimungkinkan oleh faktor genetik dari tanaman. Hal tersebut didasari oleh pendapat Sumenda et al. (2011) yang mengatakan bahwa pertumbuhan dan perkembangan tanaman dapat dipengaruhi faktor internal dimana salah satunya adalah faktor genetik. Walaupun berat segar akar tidak berpengaruh nyata terhadap semua perlakuan, akar selada tetap melakukan penyerapan mineral dengan baik. Selain karena kondisi nutrisi $\mathrm{AB}$ mix yang mendukung, panjang akar yang berpengaruh nyata terhadap penambahan penyinaran cahaya. Hal ini sesusai dengan pendapat dari Polnaya dan Lesilolo (2012) yang mengatakan bahwa panjang akar, luas permukaan akar dan juga konduktivitas pembuluh pada akar membantu penyerapan air dan mineral (material untuk proses fotosintesis) dan secara tidak langsung meningkatkan berat segar. Keadaan yang seharusnya diperoleh adalah ketika tinggi tanaman berbeda nyata, berat segar ikut berbeda nyata. Hal tersebut didukung oleh pendapat Kinasihati (2008) yang menyatakan bahwa peningkatan berat segar tanaman disebabkan oleh peningkatan tinggi tanaman dan jumlah daun yang termasuk sebagai bagian vegetatif tanaman.

\section{Berat Kering}

Berdasarkan hasil analisis ragam berat kering, diperoleh hasil bahwa berat kering dan rasio tajuk akar tidak nyata dipengaruhi konsentrasi $\mathrm{AB}$ mix maupun penyinaran lampu LED. Data hasil pengujian disajikan pada Tabel 2.

Berdasarkan hasil dari uji lanjut BNJ berat tanaman tersaji pada Tabel 2, berat kering tajuk, akar, total dan rasio akar tajuk tidak menunjukkan perbedaan nyata terhadap perlakuan lama penyinaran lampu LED pada berbagai taraf. Hal ini diduga karena penyinaran hanya dilakukan pada seperempat panjang harinya saja, yaitu pada malam hari. Berkaitan dengan hal tersebut, Waycott (1995) berpendapat hal serupa bahwa selada merupakan tanaman yang memiliki reaksi terhadap cahaya di hari panjang, dimana pertumbuhannya dan perkembanganya melebihi dari 12 jam intensitas penyinaran cahaya. Hal yang seharusnya terjadi adalah, pemberian cahaya tambahan tanaman hari panjang dapat meningkatkan berat kering, karena menurut pendapat Sutoyo (2011) yang menyatakan pemberian perlakuan pada fotoperiodisme dapat meningkatkan pertumbuhan dan perkembangan tanaman hari panjang. Pendapat dari penulis lain yaitu Nishimura et al. (2009) yang berpendapat bahwa pemberian cahaya merah dapat meningkatkan fotosintesis, yang menyebabkan penambahan berat kering.

\section{Rasio Tajuk Akar}

Berdasarkan hasil analisis ragam rasio tajuk akar, diperoleh hasil rasio tajuk akar tidak nyata dipengaruhi konsentrasi $\mathrm{AB}$ mix maupun 
Tabel 2. Produksi Berat Kering akibat Penyinaran Lampu LED

\begin{tabular}{|c|c|c|c|c|}
\hline \multirow{2}{*}{$\begin{array}{l}\text { Penyinaran } \\
\text { Lampu LED }\end{array}$} & \multirow{2}{*}{$\begin{array}{c}\text { Konsentrasi } \mathrm{AB} \\
\text { Mix } \\
\end{array}$} & \multicolumn{3}{|c|}{ Rerata Berat Kering } \\
\hline & & Tajuk & Akar & Total \\
\hline \multirow[t]{2}{*}{......(jam)....... } & $\ldots . . .(\mathrm{ml} / \mathrm{l}) \ldots . .$. & \multicolumn{3}{|c|}{ 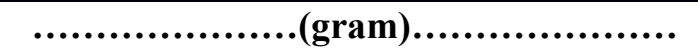 } \\
\hline & 3 & 4,60 & 1,04 & 5,64 \\
\hline \multirow{4}{*}{0} & 5 & 2,46 & 0,83 & 3,29 \\
\hline & 7 & 3,09 & 0,61 & 3,70 \\
\hline & Rata-rata & $3,39^{\mathrm{a}}$ & $0,82^{\mathrm{a}}$ & $4,21^{\mathrm{a}}$ \\
\hline & 3 & 3,66 & 1,27 & 4,92 \\
\hline \multirow{2}{*}{1,5} & 5 & 3,90 & 1,19 & 5,09 \\
\hline & 7 & 4,05 & 1,27 & 5,32 \\
\hline \multirow{5}{*}{3} & Rata-rata & $3,87^{\mathrm{a}}$ & $1,24^{\mathrm{a}}$ & $5,11^{\mathrm{a}}$ \\
\hline & 3 & 3,33 & 0,92 & 4,25 \\
\hline & 5 & 4,09 & 0,93 & 5,02 \\
\hline & 7 & 4,26 & 1,04 & 5,30 \\
\hline & Rata-rata & $3,89^{\mathrm{a}}$ & $0,96^{\mathrm{a}}$ & $4,86^{\mathrm{a}}$ \\
\hline \multicolumn{2}{|c|}{ Respon } & tn & tn & tn \\
\hline \multicolumn{2}{|c|}{ KK $(\%)$} & 14,68 & 17,20 & 28,21 \\
\hline
\end{tabular}

Keterangan : tn : tidak berbeda nyata; KK : koefisien keragaman; Angka yang diikuti oleh huruf yang sama pada kolom yang sama menunjukkan berbeda tidak nyata pada taraf 5\% menurut Uji Beda Nyata Jujur (BNJ).

Tabel 3. Rasio Tajuk Akar akibat Penyinaran Lampu LED

\begin{tabular}{|c|c|c|}
\hline Penyinaran Lampu LED & Konsentrasi AB Mix & Rerata Rasio Tajuk Akar \\
\hline \multirow[t]{2}{*}{.........(jam)......... } & $\ldots \ldots .(\mathrm{ml} / \mathrm{l}) \ldots . .$. & ..................(gram).................... \\
\hline & 3 & 2,00 \\
\hline \multirow{4}{*}{0} & 5 & 5,13 \\
\hline & 7 & 10,20 \\
\hline & Rata-rata & $5,78^{\mathrm{a}}$ \\
\hline & 3 & 16,04 \\
\hline \multirow{4}{*}{1,5} & 5 & 3,12 \\
\hline & 7 & 8,41 \\
\hline & Rata-rata & $9,19^{\mathrm{a}}$ \\
\hline & 3 & 3,81 \\
\hline \multirow{3}{*}{3} & 5 & 3,52 \\
\hline & 7 & 6,27 \\
\hline & Rata-rata & $4,54^{\mathrm{a}}$ \\
\hline \multicolumn{2}{|c|}{ Respon } & tn \\
\hline \multicolumn{2}{|c|}{ KK $(\%)$} & 51,83 \\
\hline
\end{tabular}

Keterangan : * : berbeda nyata; HST : hari setelah tanam; KK : koefisien keragaman; Angka yang diikuti oleh huruf yang sama pada kolom yang sama menunjukkan berbeda tidak nyata pada taraf $5 \%$ menurut Uji Beda Nyata Jujur (BNJ). 
penyinaran lampu LED. Data hasil pengujian disajikan pada Tabel 3.

Berdasarkan hasil dari uji lanjut BNJ rasio tajuk akar yang tersaji pada Tabel 3, diketahui rasio akar dan tajuk tidak menunjukan pengaruh terhadap konsentrasi $\mathrm{AB}$ mix dan pemberian cahaya lampu LED di malam hari. Hal tersebut menunjukan bahwa semua perlakuan pada tanaman selada tidak memberikan peningkatan yang cukup pada pertumbuhan masing-masing organ, termasuk penambahan pada berat kering tajuk. Rasio akar tajuk merupakan perbandingan berat kering tajuk dan akar, apabila berat kering tajuk tidak lebih besar dari berat kering akar, maka hasil analisis rasio akar tajuk tidak akan menunjukan pengaruh nyata. Berat kering tajuk dan akar tak menunjukan berpengaruh nyata terhadap perlakuan yang diberikan. Hal ini menunjukan pertumbuhan berat kering tanaman tidak seimbang. Pernyataan ini didukung oleh Ginting (2010) yang berpendapat bahwa berat kering tanaman sangat ditentukan pertumbuhan berat kering masing-masing organ yang menyusun tubuh tanaman tersebut, sehingga apapun perlakuan yang diberikan pertumbuhan akar dan batang dalam membentuk tubuh atau individu tanaman tersebut harus terjadi secara seimbang. Hasil dari analisis rasio tajuk akar yang tidak berpengaruh nyata terhadap penambahan penyinaran cahaya dapat terjadi karena tingkat pendistribusian fotosintat ke tajuk kurang, sehingga tanaman dengan perlakuan (1,5 dan 3 jam) menunjukan hasil yang sama dengan tanaman tanpa perlakuan penambahan cahaya ( 0 $\mathrm{jam} / \mathrm{kontrol}$ ). Hal ini sesuai dengan pendapat Polnaya dan Lesilolo (2012) yang mengatakan bahwa rasio tajuk akar dipengaruhi tingkat pendistribusian fotosintat ke tajuk yang otomatis berpengaruh pada berat kering tajuk.

\section{KESIMPULAN}

Hasil dari penelitian memperlihatkan bahwa perlakuan konsentrasi nutrisi ab mix tidak berpengaruh nyata terhadap semua paramater. Produksi selada dengan taraf $5 \mathrm{ml}$ konsentrasi AB mix telah cukup memberikan hasil yang baik, namun taraf $3 \mathrm{ml}$ dan $7 \mathrm{ml}$ tidak menambahkan hasil produksi selada. Durasi penyinanaran lampu LED merah dan biru, hanya menghasilkan peningkatan produksi berat segar tajuk. Penelitian dapat diambil kesimpulan yaitu 3 jam sudah cukup memberikan hasil yang baik untuk meningkatkan hasil produksi tanaman selada.

\section{DAFTAR PUSTAKA}

Badan Pusat Statistik (BPS). 2010. Tabel Hasil Sensus Penduduk 2010 (online) http://www.bps.go.id/aboutus.php?sp=0. [28 April 2016].

Gardner, P. F., B. R. Pearce, dan R. L. Mitchell. 2007. Fisiologi Tanaman Budidaya. Terjemahan oleh Herawati, S. Universitas Indonesia, Jakarta.

Ginting, C. 2010. Kajian biologis tanaman selada dalam berbagai kondisi lingkungan pada sistem hidoponik. Jurnal Agriplus. 20 (20) : 107-113.

Guritno, B. dan Sitompul. 2006. Analisis Pertumbuhan Tanaman. Fakultas Pertanian, Universitas Brawijaya, Malang.

Kinasihati, E. 2008. Studi Kebutuhan Nitrogen Tanaman Selada. Universitas Jember, Jember.

Nishimura, T., K. Ohyama, E. Goto, and N. Inagaki. 2009. Concentrations of perillaldehyde, limonene, and anthocyanin of Perilla plants as affected by light quality under controlled environments. Scientia Horticulturae. 122 : 134-137.

Polnaya, F. dan M.K. Lesilolo. 2012. Pengaruh konsentrasi pupuk green tonik dan waktu pemberian pupuk terhadap pertumbuhan bibit kakao (Theobroma cacao L.) Jurnal Budidaya Pertanian. 8 (1) : 31-38.

Samanhudi dan D. Harjoko. 2006. Pengaturan Komposisi Nutrisi dan Media dalam Budidaya Tanaman Tomat dengan Sistem Hidroponik. Jurusan Agronomi Fakultas Pertanian, Universitas Surakarta, Surakarta. 
Sumenda, L., H.L Rampe, dan F.R. Mantiri. 2011. Analisis kandungan klorofil daun mangga (Mangifera indica L.) pada tingkat perkembangan daun yang berbeda. Jurnal Bioslogos. 1 (1) : 20-24.

Sutoyo. 2011. Fotoperiode dan pembungaan tanaman. J. Buana Sains. 11 (2): 137-144.

Waycott, W. 1995. Photoperiodic response of genetically diverse lettuce accessions. Journal of the American Society for Horticultural Science. 120 (3) : 460-467. 